\title{
INTERAÇÃO NÍVEL DE BASE E DISSECAÇÃO DE BACIAS HIDROGRÁFICAS NO SUDESTE DE MINAS GERAIS - BRASIL
}

\author{
Breno Ribeiro Marent \\ Universidade Federal de Minas Gerais, Instituto de Geociências, Belo Horizonte, MG, Brasil \\ brenomarent@gmail.com \\ Roberto Célio Valadão \\ Universidade Federal de Minas Gerais, Instituto de Geociências, Belo Horizonte, MG, Brasil \\ valadao@ufmg.br \\ Luiz Augusto Manfré \\ Universidade de São Paulo, Departamento de Engenharia de Transportes, São Paulo, SP, Brasil \\ luizmanfre@gmail.com \\ Rodrigo Affonso de Albuquerque Nóbrega \\ Universidade Federal de Minas Gerais, Instituto de Geociências, Belo Horizonte, MG, Brasil \\ raanobrega@ufmg.br \\ Renata Jordan Henriques \\ Universidade Federal de Minas Gerais, Instituto de Geociências, Belo Horizonte, MG, Brasil \\ renatajhques@gmail.com
}

\begin{abstract}
RESUMO
As bacias hidrográficas da porção oriental do território brasileiro apresentam marcante discrepância escalar dimensional. Aquelas bacias voltadas para o interior continental apresentam grandes extensões, distinguindo-se daquelas costeiras de menor área drenada. Esses grupamentos de bacias são separados por um Grande Escarpamento, herança de processos tectônicos e denudacionais mesocenozoicos. No sudeste de Minas Gerais esse escarpamento separa bacias ajustadas e organizadas, em planta e perfil, a degraus escalonados aqui reconhecidos e mapeados mediante geotecnologias. A geomorfodinâmica vigente nesses degraus responde a distintos níveis de base, de modo que as análises efetivadas neste trabalho se fundamentam na elaboração de mapeamentos que demonstram a estreita relação entre a dimensão regional do relevo e a organização da rede de drenagem. Conclui-se aqui que, além de os distintos níveis de base condicionarem fortemente a denudação continental no sudeste mineiro, o Grande Escarpamento configura importante fronteira que individualiza domínios geomorfológicos em que vigoram condições discrepantes quanto ao comportamento espaço-temporal da incisão da rede hidrográfica regional. Nas bacias interiores os canais fluviais revelam desníveis altimétricos significativamente menores que aqueles das bacias que se dirigem diretamente para o oceano. Naquelas bacias costeiras, a dissecação do relevo está organizada segundo degraus escalonados de extensão sub-regional, ausentes nas bacias interiores.
\end{abstract}

Palavras-chave: Grande Escarpamento. Dissecação do Relevo. Denudação Continental. Knickpoints.

\section{INTERACTION BASE LEVEL AND DISSECTION OF HYDROGRAPHIC BASINS IN THE SOUTHEAST OF MINAS GERAIS - BRAZIL}

\begin{abstract}
The hydrographic basins of the eastern portion of the Brazilian territory present a remarkable dimensional scalar discrepancy. Those basins located in the interior of the continent have large extensions, unlike those that occupy coastal position that have smaller area drained. These distinct sets of basins are separated by a Great Escarpment, inheritance of tectonic and denudational processes that occurred during the opening of the South Atlantic in the Mesocenozoic. In the southeast of the state of Minas Gerais this escarpment separates hydrographic basins that are adjusted and organized, in plan and profile, to stepped steps clearly recognized and mapped here using geotechnologies. The current geomorphodynamics in these steps responds to the different levels of base to which its hydrographic basins are articulated. The analyzes elaborated in this work are based on
\end{abstract}


mappings that aim to express the close relationship between the regional dimension of relief and the organization of the drainage network. It is demonstrated here that, in addition to the fact that different levels of base strongly influence continental denudation in the southeast of Minas Gerais, the Great Escarpment forms a prominent and important frontier that separates two geomorphological domains in which there are discrepant conditions regarding the behavior in space and time incision of the regional hydrographic network. The river channels that integrate the inner basins reveal significantly lower altimetric slopes than those of the rivers that go directly to the ocean. In those coastal basins, the relief dissection is spatially organized according to staggered steps of subregional extension, which are absent in the interior basins.

Keywords: Great Escarpment. Dissection of the Relief. Continental Denudation. Knickpoints.

\section{INTRODUÇÃO}

Relevos adjacentes a margens continentais passivas maduras que contêm grandes escarpas, tal como no Brasil oriental, ocorrem em outras áreas do globo, a exemplo do sudoeste e sudeste da África, oeste da Índia e leste da Austrália. Na literatura geomorfológica essas feições são comumente designadas Grande Escarpamento, consistindo de amplas elevações paralelas à costa, formadas a partir de rifteamentos cuja evolução espaço-temporal culminou na ruptura continental e na geração de uma rede de drenagem dual (SUMMERFIELD, 1991; GILCHRIST et al. 1994; VALADÃO, 1998; 2009; MATMON et al., 2002). Esses escarpamentos separam áreas mais rebaixadas e adjacentes à costa daquelas áreas mais elevadas que configuram um planalto interior. Tal fato gera diferentes níveis de base em ambos os lados dessas elevações. Segundo Gilchrist e Summerfield (1990) e Valadão (1998), o nível de base altimetricamente mais baixo em um dos lados desses escarpamentos comandaria sua evolução, mediante a mais acentuada denudação naquelas porções de maior declividade e amplitude.

No Brasil oriental esse escarpamento teve sua gênese relacionada à tectônica mesocenozoica, a qual exerceu papel fundamental na organização espacial e na dinâmica das bacias hidrográficas que atualmente ocupam posição adjacente à margem continental oriental brasileira (ALMEIDA, 1976; VALADÃO, 1998; ZALÁN; OLIVEIRA, 2005). Em distintas porções da margem oriental brasileira, Valadão (2009) e Salgado et al. (2014) verificaram o rejuvenescimento do relevo decorrente do nível de base mais baixo nas bacias costeiras. Em outras porções do globo conformação semelhante foi identificada por Thomas e Summerfield (1987), Gilchrist e Summerfield (1990), Ollier e Pain (1997) e Gilchrist et al. (1994). É nesse contexto que se insere a área investigada neste trabalho, tendo em vista abranger trechos de bacias hidrográficas do Sudeste brasileiro que drenam tanto em direção ao interior continental (São Francisco; Paraná), quanto diretamente para o oceano (Doce; Paraíba do Sul) (Figura 1).

Os conjuntos de bacias I e II individualizados na Figura 1 são, na área de estudo, separados por um Grande Escarpamento, de fácil reconhecimento na paisagem, em imagens orbitais e, sobretudo, em modelos de elevação digital do terreno. Além da peculiaridade da presença desse escarpamento, destaca-se, nessa área, a ocorrência de três degraus topográficos escalonados cuja distribuição espacial está em plena conformidade com a distribuição espacial das bacias hidrográficas, conforme já salientado por Cherem (2012) e Marent e Valadão (2015). As grandes bacias hidrográficas que drenam em direção ao interior continental constituem o degrau superior, enquanto as bacias que drenam diretamente para o oceano se organizam em degraus distintos posicionados em nível altimétrico intermediário, na bacia do rio Doce, e inferior, na bacia do rio Paraíba do Sul. Nesse conjunto de bacias, Salgado et al. (2012) e Cherem et al. (2012) identificaram maiores taxas de denudação nas bacias costeiras em relação às bacias do interior continental. Além disso, foram verificadas taxas de denudação mais elevadas na bacia costeira do rio Paraíba do Sul, que se encontra em nível de base mais baixo, em relação à bacia do rio Doce. Porém, a espacialidade dessas análises se restringiu a áreas próximas à escarpa.

$\begin{array}{llllll}\text { Caminhos de Geografia } & \text { Uberlândia - MG } & \text { v. 19, n. } 68 & \text { Dez/2018 } & \text { p. 215-232 } & \text { Página } 216\end{array}$


Figura 1: Localização da área de estudo segundo distribuição espacial das bacias hidrográficas dos rios São Francisco, Paraná, Doce e Paraíba do Sul no território brasileiro. Observe que as duas primeiras bacias apresentam grandes extensões e ocupam posição interior (I), contrastando sobremaneira com a extensão mais reduzida das duas últimas (II), as quais drenam diretamente para o oceano e ocupam posição costeira.

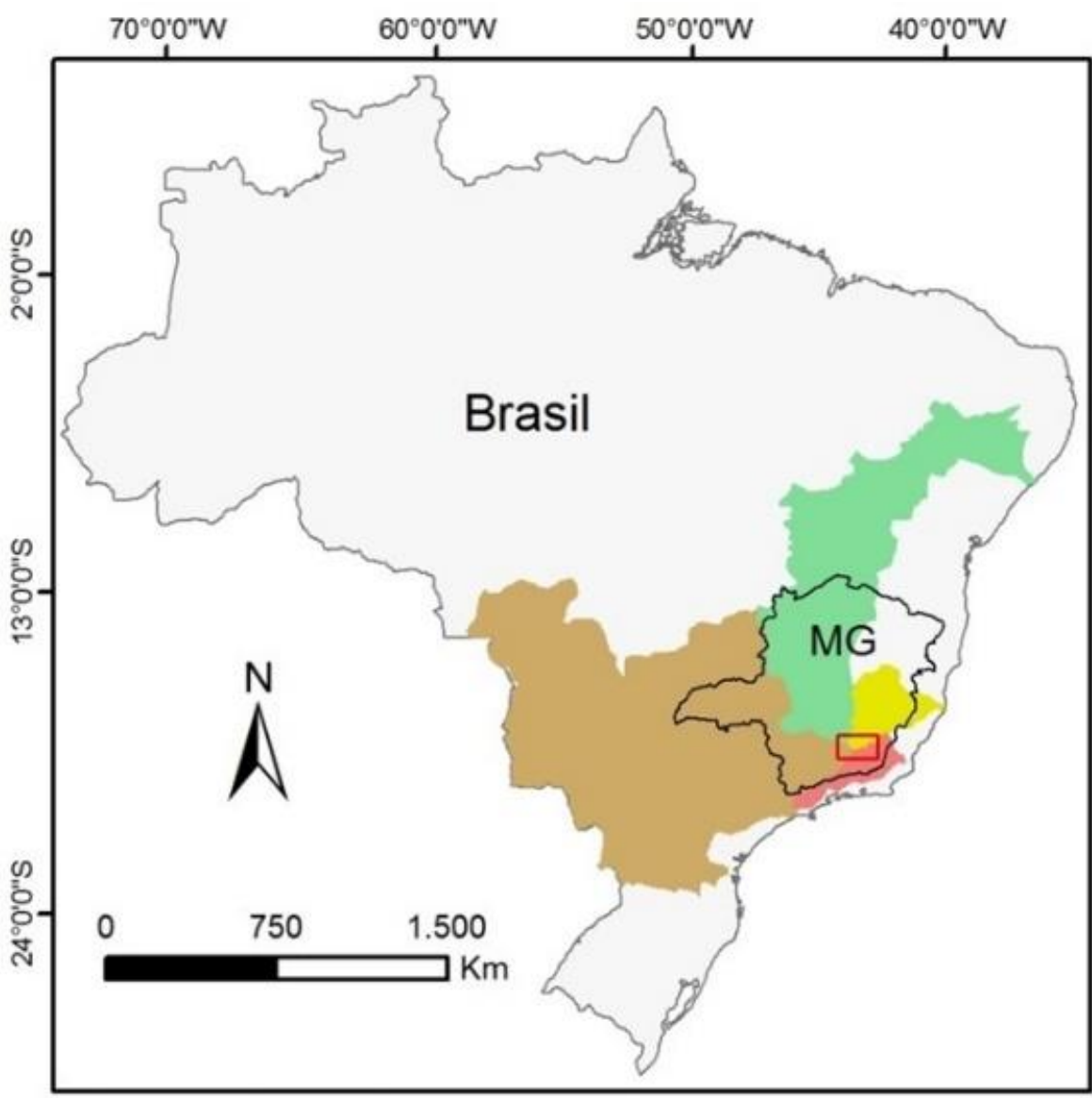

Área de estudo

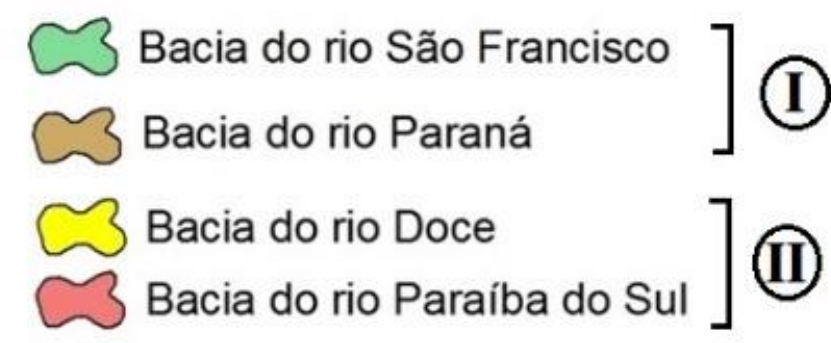

Ao que tudo indica, nessa organização em degraus, a diferença de nível de base ao qual a denudação continental está submetida desempenhou papel fundamental na incisão vertical da rede hidrográfica na medida em que uma vaga erosiva, partindo do litoral, adentrou o continente e promoveu não só o rebaixamento do planalto elevado com a respectiva formação do Grande Escarpamento, como também individualizou degraus escalonados perfeitamente ajustados aos limites das bacias hidrográficas. Embora a organização em degraus dessas bacias já ter sido reconhecida na literatura, permanecem ainda questionamentos acerca de sua gênese, com destaque para a dinâmica espaço-temporal dos processos responsáveis pela produção de marcante cenário geomorfológico do Sudeste brasileiro. É nesse contexto que se insere este trabalho, cujo objetivo está voltado para a análise de possíveis influências exercidas pelo nível de base em diferentes 
escalas espaciais no estabelecimento de destacado escarpamento regional através da dissecação das bacias hidrográficas e consequente geração de distintos degraus topográficos, bem como dos elementos associados à organização e significado de sua rede hidrográfica.

\section{MATERIAIS E MÉTODOS}

A execução deste trabalho teve início na consulta de dados e informações disponíveis na literatura geológica e geomorfológica sobre a área investigada. Seu desenvolvimento teve prosseguimento por meio da utilização de elementos geomorfológicos que possibilitaram a confecção de modelo de elevação digital do terreno (MDE) com hipsometria (Figura 3), mapa de dissecação do relevo (Figura 4), perfis longitudinais dos principais cursos fluviais das bacias costeiras (Figuras 5, 7 e 8) e mapa dos principais lineamentos estruturais regionais das bacias costeiras (Figura 9). Com vistas a subsidiar as análises desses produtos e sua relação com a organização e funcionalidade do relevo e drenagem foram levantados dados quantitativos acerca das bacias hidrográficas que compõem a área de estudo, como dimensão, amplitude e extensão dos canais principais das bacias costeiras (Figuras 6, 7 e 8; Tabela 1). O reconhecimento e caracterização dos cenários geomorfológicos que vigoram nos distintos degraus topográficos, bem como nos proeminentes escarpamentos, foram avaliados durante campanhas de trabalho de campo.

Para a produção do MDE empregou-se o Shuttle Radar Topography Mission (SRTM), com resolução de 30 metros, da base Topodata (INPE, 2011). A base SRTM juntamente com arquivos da rede de drenagem no formato shapefile do software de geoprocessamento ArcGis, disponível no site da Agência nacional de Águas (ANA, 2014), foi utilizada para confecção de perfis longitudinais dos principais cursos fluviais que drenam a área investigada. A amplitude desses cursos foi obtida a partir da base Topodata (INPE, 2011) associada a arquivos da rede hidrográfica (ANA, 2014) e imagens de satélite de alta resolução Google Earth Pro. A área das bacias hidrográficas foi obtida a partir de arquivos disponíveis no site da Agência nacional de Águas (ANA, 2014).

$\mathrm{Na}$ confecção do mapa de dissecação se utilizou de procedimentos contidos em Manfré et al. (2015) com vistas à compartimentação do relevo regional, empregando-se SRTM da base Topodata (INPE, 2011). Para o processo de segmentação foram utilizadas a elevação numérica (ZN), declividade (SN), curvatura vertical (VN), curvatura horizontal (HN) e a densidade de drenagem (DD) (Figura 2). O uso dessas informações segue o pressuposto da subdivisão do relevo natural e tenta tornar mais evidentes suas características topográficas (VALERIANO, 2003; VALERIANO; CARVALHO JÚNIOR, 2003). A segmentação foi executada conforme Dragut e Eisank (2012), baseada no processo de classificação OBIA (Object-based Image Analysis), ajustando fatores de forma e de compacidade para zero, eliminando, assim, os efeitos de quaisquer formas definidas sobre os objetos de imagem. Para preservar os parâmetros de análise, um fator de escala de 10 foi usado, o que permitiu a distinção de pequenas áreas homogêneas do relevo.

A elevação constituiu o elemento base a partir do qual foram obtidas as demais variáveis geomorfológicas. Na classificação a declividade foi considerada como primeiro nível de acordo com as classes definidas pelo IBGE (2009), até $8 \%$ baixa, entre 8 e $20 \%$ intermediária, entre 20 e $45 \%$ elevada e acima de $45 \%$ muito elevada. Para o segundo nível foram definidas classes de acordo com a orientação da curvatura vertical (côncava ou convexa). Para o terceiro nível, a curvatura horizontal foi utilizada para a redefinição das classes finais, normatizada de acordo com sua orientação (côncava ou convexa).

A análise dos elementos (dimensão, amplitude e extensão) da rede de drenagem baseou-se nos trabalhos de Valadão (1998) e Salgado et al. (2014), os quais utilizaram desses elementos para investigar a organização e significado da rede hidrográfica relacionada ao Grande Escarpamento em diferentes partes do Brasil, respectivamente no Nordeste e Sul do país. Entretanto, nesse trabalho utilizou-se de abordagem que estabelece a relação entre esses elementos e a topografia exibida em MDE com hipsometria e mapa de dissecação.

$\begin{array}{llllll}\text { Caminhos de Geografia } & \text { Uberlândia - MG } & \text { v. 19, n. } 68 & \text { Dez/2018 } & \text { p. 215-232 } & \text { Página } 218\end{array}$


Figura 2: Esquema de árvore de decisão com base nas informações de elevação (média e desvio padrão) e suas derivações. DD: densidade de drenagem, ZN: elevação numérica, SN: declividade, $\mathrm{VN}$ : curvatura vertical e $\mathrm{HN}$ : curvatura horizontal.

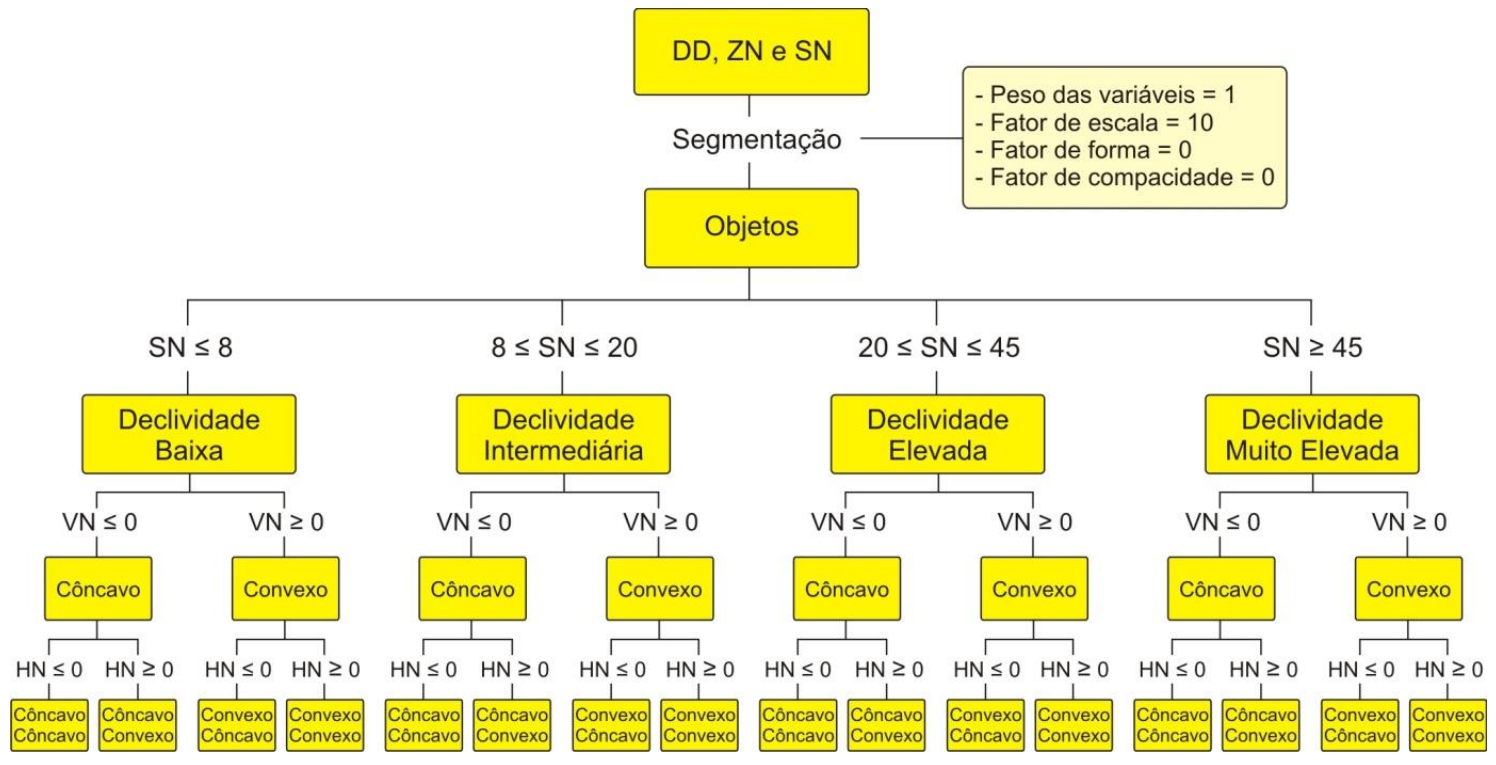

A elevação constituiu o elemento base a partir do qual foram obtidas as demais variáveis geomorfológicas. Na classificação a declividade foi considerada como primeiro nível de acordo com as classes definidas pelo IBGE (2009), até $8 \%$ baixa, entre 8 e $20 \%$ intermediária, entre 20 e $45 \%$ elevada e acima de $45 \%$ muito elevada. Para o segundo nível foram definidas classes de acordo com a orientação da curvatura vertical (côncava ou convexa). Para o terceiro nível, a curvatura horizontal foi utilizada para a redefinição das classes finais, normatizada de acordo com sua orientação (côncava ou convexa).

A análise dos elementos (dimensão, amplitude e extensão) da rede de drenagem baseou-se nos trabalhos de Valadão (1998) e Salgado et al. (2014), os quais utilizaram desses elementos para investigar a organização e significado da rede hidrográfica relacionada ao Grande Escarpamento em diferentes partes do Brasil, respectivamente no Nordeste e Sul do país. Entretanto, nesse trabalho utilizou-se de abordagem que estabelece a relação entre esses elementos e a topografia exibida em MDE com hipsometria e mapa de dissecação.

\section{RESULTADOS E DISCUSSÕES}

\section{ANÁLISE DO RELEVO}

O mapa hipsométrico da área investigada demonstra que seu relevo contempla compartimentos morfométricos diferenciados, cuja espacialidade revela marcada conformidade quanto a distribuição das bacias hidrográficas (Figura 3). Distinguem-se, em uma primeira ordem de grandeza, dois conjuntos de bacias, um composto por bacias que drenam para o interior continental (São Francisco; Paraná) e, um outro, por aquelas que drenam diretamente para o oceano (Doce; Paraíba do Sul). Quanto a esse último conjunto se distinguem em seu interior, em uma segunda ordem de grandeza, dois degraus escalonados, cada qual também justaposto às bacias hidrográficas que os drenam. A topografia exibe predomínio de altitudes que se situam entre 900 e $1.200 \mathrm{~m}$ no degrau superior (São Francisco; Paraná), 600 a 900 m no degrau intermediário (Doce) e 140 a 600 m no degrau inferior (Paraíba do Sul). Em todas essas bacias hidrográficas se verifica decréscimo da altitude a partir de seus divisores hidrográficos. Separando as bacias que drenam para o interior continental daquelas que drenam diretamente para o oceano ocorre um Grande Escarpamento que exibe diferenciada amplitude altimétrica. Junto ao divisor das bacias do São Francisco e Doce ocorre escarpa de $\sim 250 \mathrm{~m}$

$\begin{array}{llllll}\text { Caminhos de Geografia } & \text { Uberlândia - MG } & \text { v. 19, n. } 68 & \text { Dez/2018 } & \text { p. 215-232 } & \text { Página } 219\end{array}$


de altura, ao passo que no divisor entre as bacias do Paraná e Doce ela chega a alcançar $\sim 400 \mathrm{~m}$ e, entre as bacias do Paraná e Paraíba do Sul, sua altura varia de 250 a 500 m. Esse último trecho é parte integrante da Serra da Mantiqueira, a qual se prolonga pelo divisor entre as bacias dos rios Doce e Paraíba do Sul e exibe escarpa com $\sim 300 \mathrm{~m}$ de desnível.

Figura 3: Mapa hipsométrico da área de estudo, em que se distinguem degraus topográficos escalonados cuja distribuição espacial revela marcada conformidade com a área ocupada pelas principais bacias hidrográficas. Observe que essa conformidade se revela também entre os principais divisores hidrográficos e os escarpamentos.

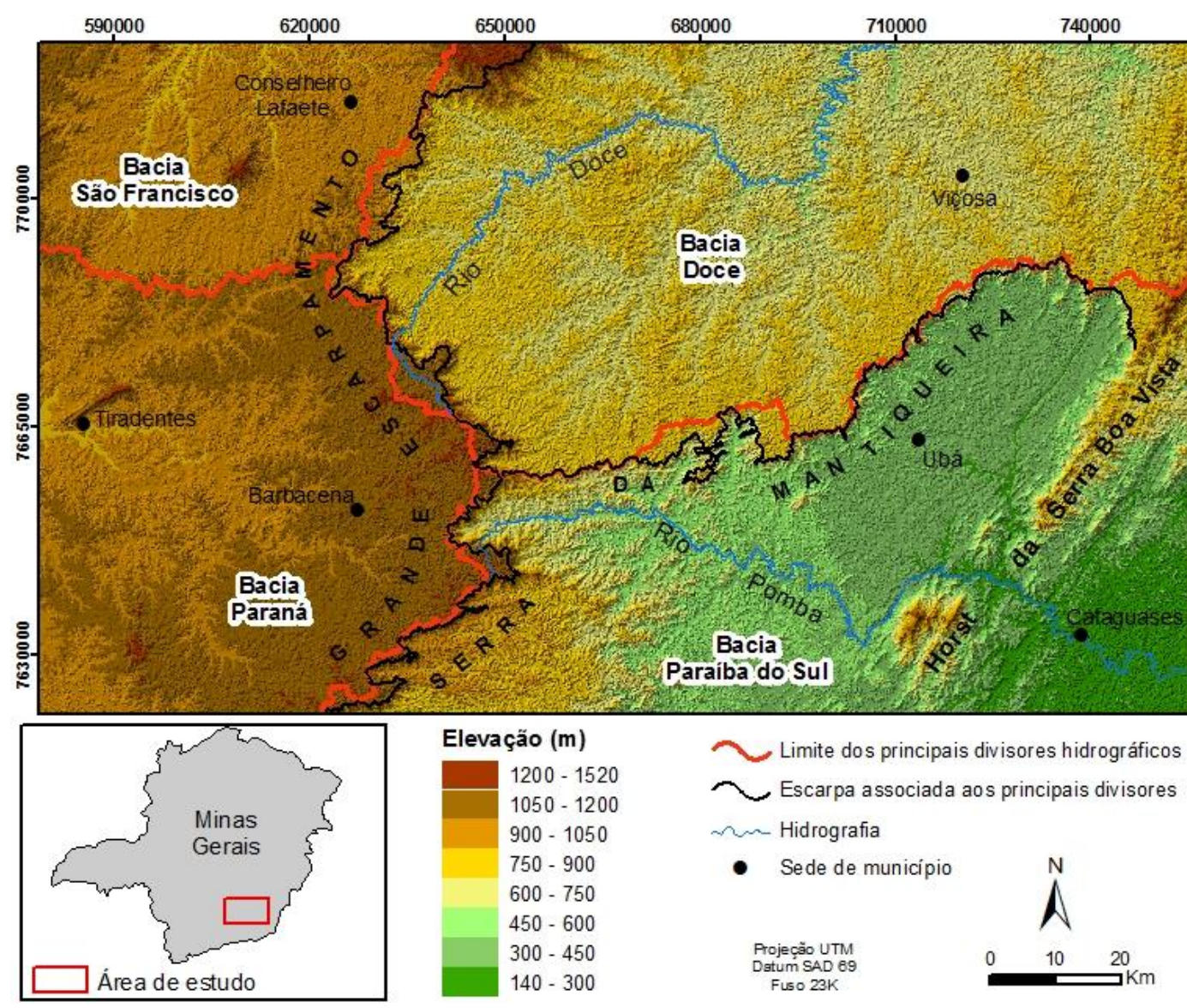

Todavia, na bacia do Paraíba do Sul, a SW, ocorre área de significativa expressão espacial, adjacente à bacia do rio Paraná, constituindo planalto intermediário a altitudes predominantes entre 750 e $900 \mathrm{~m}$, semelhantes à bacia do Doce (Figura 3). A manutenção dessa superfície, segundo Marent e Valadão (2015), se deve a existência de rochas mais resistentes à denudação (enderbitos gnáissicos, charnockitos e granitos) que sustentam níveis de base locais mais elevados. A leste encontra-se outra superfície elevada, no alinhamento serrano de direção NESW, com altitudes que predominam entre 700 e $1000 \mathrm{~m}$, mas que podem chegar a $1520 \mathrm{~m}$. Esse alinhamento foi designado por Romano e Castañeda (2006) Horst da Serra da Boa Vista, um pilar tectônico constituído por gnaisses enderbíticos, paragnaisses e charnockitos que divide a depressão escalonada dos Rios Pomba e Muriaé, a NW e SE.

Estruturas compiladas por Marent e Valadão (2015) localizadas próximo a base da escarpa da Serra da Mantiqueira entre as bacias do rio Doce e Paraíba do Sul e no interior dessa última demonstram controle estrutural que pode estar associado a essas porções mais elevadas. Esse controle estrutural também pode ser verificado através do condicionamento sobre a drenagem

\begin{tabular}{llllll}
\hline Caminhos de Geografia & Uberlândia - MG & v. 19, n. 68 & Dez/2018 & p. 215-232 & Página 220
\end{tabular}


nas figuras 3 e 4, com reflexo inclusive em algumas porções do relevo. No Grande Escarpamento (área compreendida pelo limite das bacias dos rios Paraná com Paraíba do Sul, Paraná com Doce e São Francisco) não foram identificadas, em diferentes escalas, quaisquer estruturas que pudessem estar relacionadas à gênese dessa porção elevada. Entretanto, nas diferentes bacias hidrográficas autores diversos, através de análises mais detalhadas, verificaram componente tectônico atuando na configuração desses setores mais elevados.

As bacias dos rios São Francisco e Doce, que constituem o degrau mais elevado, segundo Marent e Valadão (2015) apresentam caimento geral de SE para NW. Esse caimento de acordo com Saadi (1991) estaria relacionado ao falhamento da escarpa da Serra da Mantiqueira que induziu ao basculamento generalizado da bacia do alto rio Grande (rio Paraná) e atingiu o interior do estado. Segundo Marent e Valadão (2015), a bacia do rio Doce que constitui degrau intermediário também apresenta caimento geral de SE para NW, concordante com o estabelecimento de escarpa no degrau inferior a NW. Nesse sentido, Souza (1995) já havia identificado vários blocos basculados no interior dessa bacia, no sentido NW. Na bacia do rio Paraíba do Sul, em sua porção que se destaca com prolongamento NE-SW, Mello et al. (2005) identificaram diversas falhas associadas ao basculamento de distintos blocos a SE. Esse escalonamento topográfico também foi identificado por Marent e Valadão (2015).

De forma geral, os degraus topográficos concordantes com os divisores hidrográficos podem estar associados a fatores tectônico, litológico e de nível e base, porém cada um em diferentes escalas espaciais. O componente litológico, conforme analisado por Marent e Valadão (2015), está associado a controle mais local. O elemento tectônico teria abrangência mais regional, conforme discutido anteriormente. Porém, questiona-se se somente esse seria suficiente para imprimir destacados desníveis intimamente relacionados a bacias hidrográficas e dissociados de controles estruturais regionais evidentes, como o que predomina na área de estudo. Ao que parece, o controle tectônico mais evidente se estabelece na bacia do rio Pomba/Paraíba do Sul. Apesar disso, são evidentes controles estruturais que se configuram em escala local como vagas erosivas que adentram em direção aos degraus topográficos situados em nível mais elevado, conforme pode ser evidenciado nas figuras 3 e 4, e ressaltado por Marent e Valadão (2015). Nesse sentido, o controle estrutural, seja individualizado ou pelo seu conjunto, exerce nítido condicionamento sobre a estruturação da rede de drenagem que se superimpõe estabelecendo áreas de maior denudação que são incorporadas aos degraus em posição topográfica inferior.

De forma mais evidente, a diferenciação no relevo se expressa na dissecação das vertentes verificada entre domínios espaciais distintos (Figura 4), de modo que naquelas bacias que drenam para o interior continental predomina a dissecação intermediária. Essa dissecação é representada pela topografia pouco movimentada, marcada por um conjunto de colinas. Essas colinas são caracterizadas por declividades moderadas, que variam de 8 a $20 \%$, com aprofundamento médio da rede de drenagem (IBGE, 2009). Entretanto, naquelas bacias que drenam diretamente para o oceano predomina a dissecação elevada, cuja topografia movimentada contém declividades fortes, entre $20 \%$ e $45 \%$, com aprofundamento da drenagem médio ou forte (IBGE, 2009).

A dissecação baixa está relacionada aos topos de morros mais suavizados e fundos de vale, onde ocorrem acumulações aluviais, constituindo relevo aplainado (Figura 4). É composta de topografia que varia de pouco movimentada a declives suaves, com declividades inferiores a $8 \%$ (IBGE, 2009). A dissecação muito elevada está relacionada aos relevos mais escarpados, nos quais predominam formas acidentadas e abruptas apresentando desnivelamentos relativamente grandes e declives fortes a muito fortes. As declividades são superiores a $45 \%$, onde as formações superficiais são pouco espessas ou inexistentes, podendo apresentar afloramentos rochosos (IBGE, 2009). Sua maior concentração é nas vertentes mais íngremes das bacias costeiras.

A análise conjunta dos mapas hipsométrico e de dissecação do relevo comprova a mais intensa denudação nas bacias do Doce e Paraíba do Sul, quando comparadas às bacias do São Francisco e Paraná. As bacias que drenam para o interior continental, além de ocuparem um mesmo degrau topográfico (superior), apresentam dissecação semelhante; por terem longo caminho a percorrer até - nível de base geral estão submetidas a níveis de base locais que as submetem à menor capacidade de remoção de massa. Naquelas bacias que drenam diretamente para o oceano os índices de dissecação são semelhantes, apesar de altimetricamente posicionadas em degraus

$\begin{array}{llllll}\text { Caminhos de Geografia } & \text { Uberlândia - MG } & \text { v. 19, n. 68 } & \text { Dez/2018 } & \text { p. 215-232 } & \text { Página } 221\end{array}$


topográficos distintos (intermediário e inferior). A marcante discrepância de denudação hoje vigente entre os conjuntos de bacias interioranas e costeiras denota a atuação de níveis de base distintos. $O$ fato de o limite entre esses dois conjuntos discrepantes de denudação ser estabelecido pelo Grande Escarpamento comprova que a gênese e evolução desse último esteve fortemente condicionado, em primeira instância, a fatores exógenos prontamente comandos pelo nível de base, o que não exclui, obviamente, a atuação de fatores tectônico-estruturais.

Figura 4: Mapa de dissecação do relevo da área de estudo. Observe que a variabilidade da dissecação revela aproximação considerável com dois conjuntos de bacias hidrográficas: aquelas que drenam para o interior continental (São Francisco; Paraná); as que drenam diretamente para o oceano (Doce; Paraíba do Sul).
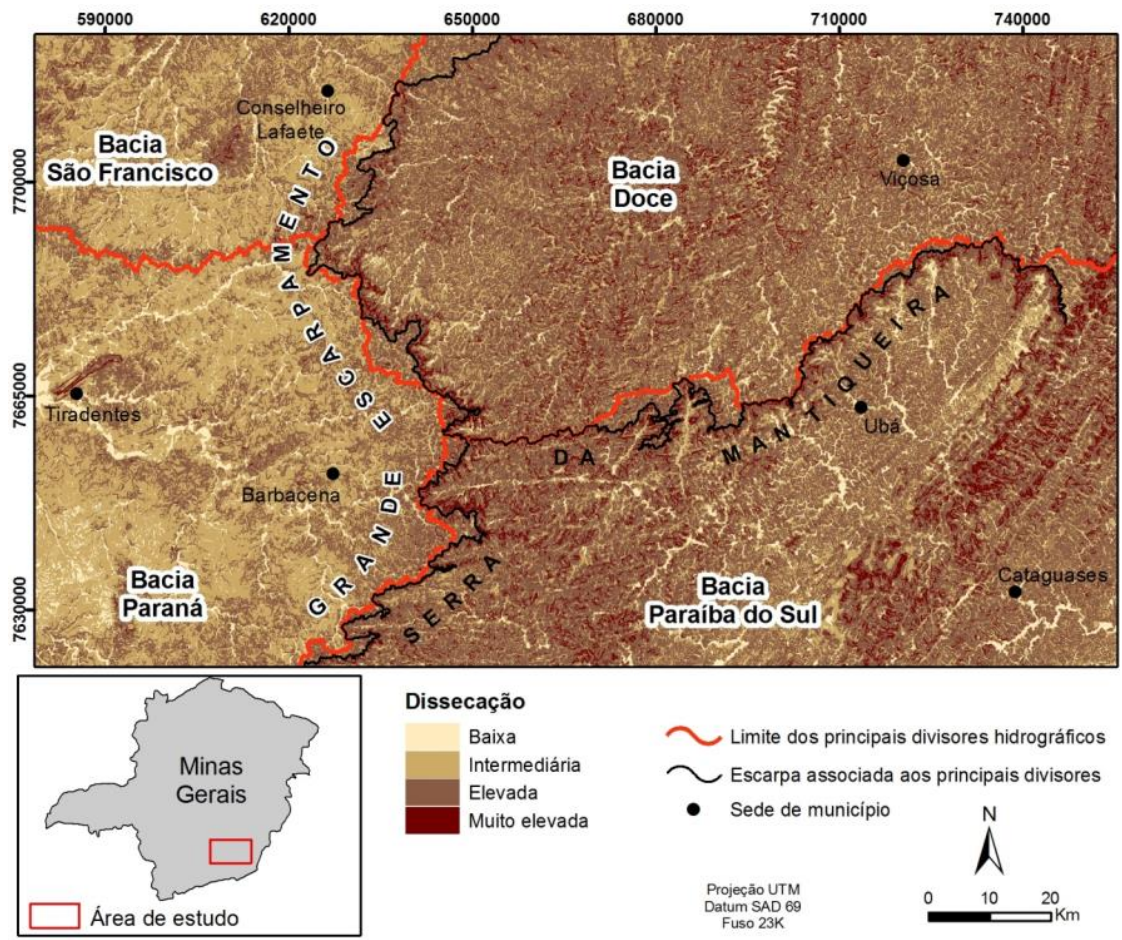

\section{ANÁLISE DA DRENAGEM}

Tendo em vista a estreita relação já verificada entre a espacialidade das bacias hidrográficas e as discrepâncias na denudação do relevo, tornou-se fundamental efetivar análise da rede hidrográfica para além do recorte espacial previamente eleito como área de estudo neste trabalho. Em recorte escalar regional mais amplo se confirmam parâmetros bastante distintos entre os conjuntos de bacias hidrográficas interioranas e costeiras, notadamente quanto à dimensão espacial, distância do nível de base oceânico e amplitude altimétrica das bacias.

As bacias do Paraná e São Francisco apresentam maior dimensão espacial do que as bacias do Doce e Paraíba do Sul, como já anteriormente salientado (Figura 1). Na área de estudo, os principais canais fluviais que integram as bacias interioranas são os rios das Mortes (sub-bacia do rio Grande; bacia do Paraná) e do Paraopeba (bacia do São Francisco) (Figura 5), todos eles posicionados acima do Grande Escarpamento. Quanto aos canais fluviais que drenam diretamente para o oceano, estão todos eles localizados abaixo desse escarpamento, destacando-se os rios Doce e Pomba, esse último afluente de margem esquerda do Rio Paraíba do Sul.

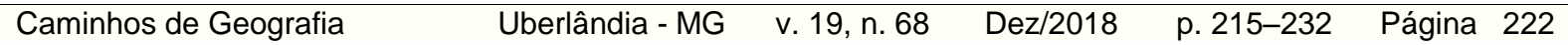


Figura 5: Organização regional da rede hidrográfica em que se insere a área de estudo.

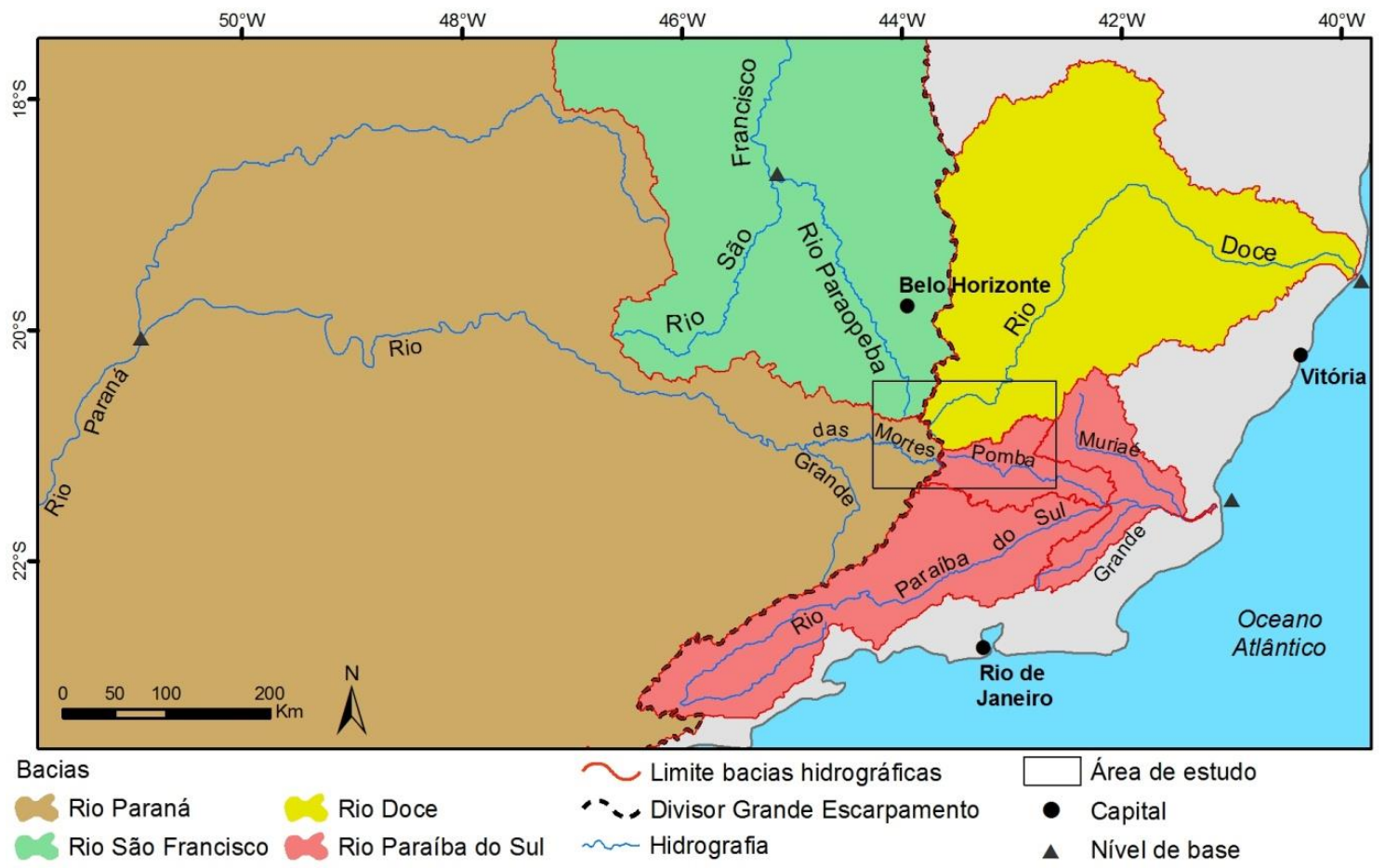

As bacias hidrográficas posicionadas topograficamente acima e abaixo do Grande Escarpamento apresentam amplitude altimétrica também discrepantes, como demonstrado na Figura 6 . As nascentes, em ambos grupos de bacias individualizados nessa figura - grupos (i) e (ii) - encontramse em cotas semelhantes, a aproximadamente $1200 \mathrm{~m}$. Os níveis de base locais dos rios das Mortes/Grande e Paraopeba se encontram, no recorte regional, respectivamente a $323 \mathrm{~m}$ de altitude no rio Paraná e, no rio São Francisco, a $567 \mathrm{~m}$ de altitude. Nas bacias costeiras o nível de base que controla a denudação regional se localiza a $0 \mathrm{~m}$, no oceano. As discrepâncias verificadas quanto a essa amplitude altimétrica é responsável, ao que tudo indica, pela contrastante denudação entre bacias interioranas e costeiras (Figura 4), tal como já verificado em outras áreas adjacentes a margens continentais passivas, seja no Brasil (VALADÃO, 1998; 2009; SALGADO et al., 2014) ou no continente africano (GILCHRIST; SUMERFIELD, 1990).

Tendo em vista o comportamento da amplitude altimétrica e da denudação na área de estudo, há indícios quanto à longevidade das discrepâncias verificadas entre ambos. VALADÃO (1998; 2009), com base na relação entre superfícies de aplanamento e registros sedimentares cronocorrelatos, já havia salientado que o Grande Escarpamento, na área investigada, teve sua origem a partir do recuo continente adentro de flancos de riftes nucleados no Mesozoico.

Estudos desenvolvidos por vários autores, entre eles Thomas e Summerfield (1987), Macedo (1989) e Valadão (1998; 2009), assumiram que após a ruptura continental a escarpa na borda elevada do rifte evoluiria por retração contínua, decorrente do elevado gradiente em relação ao interior continental. Nesse processo a escarpa coincidente com o divisor hidrográfico migraria em direção ao interior continental. Tal migração ocorreria em virtude da diferença de nível de base entre o topo da escarpa onde se localiza o divisor e o nível de base geral no oceano. Entretanto, autores como Gilchrist et al. (1994), Cockburn et al. (2000) e Nott e Horton (2000) questionaram esse modelo por recuo simples. 
Figura 6: Amplitude altimétrica dos principais canais fluviais das bacias hidrográficas localizadas topograficamente acima (i) e abaixo (ii) do Grande Escarpamento.

(m)

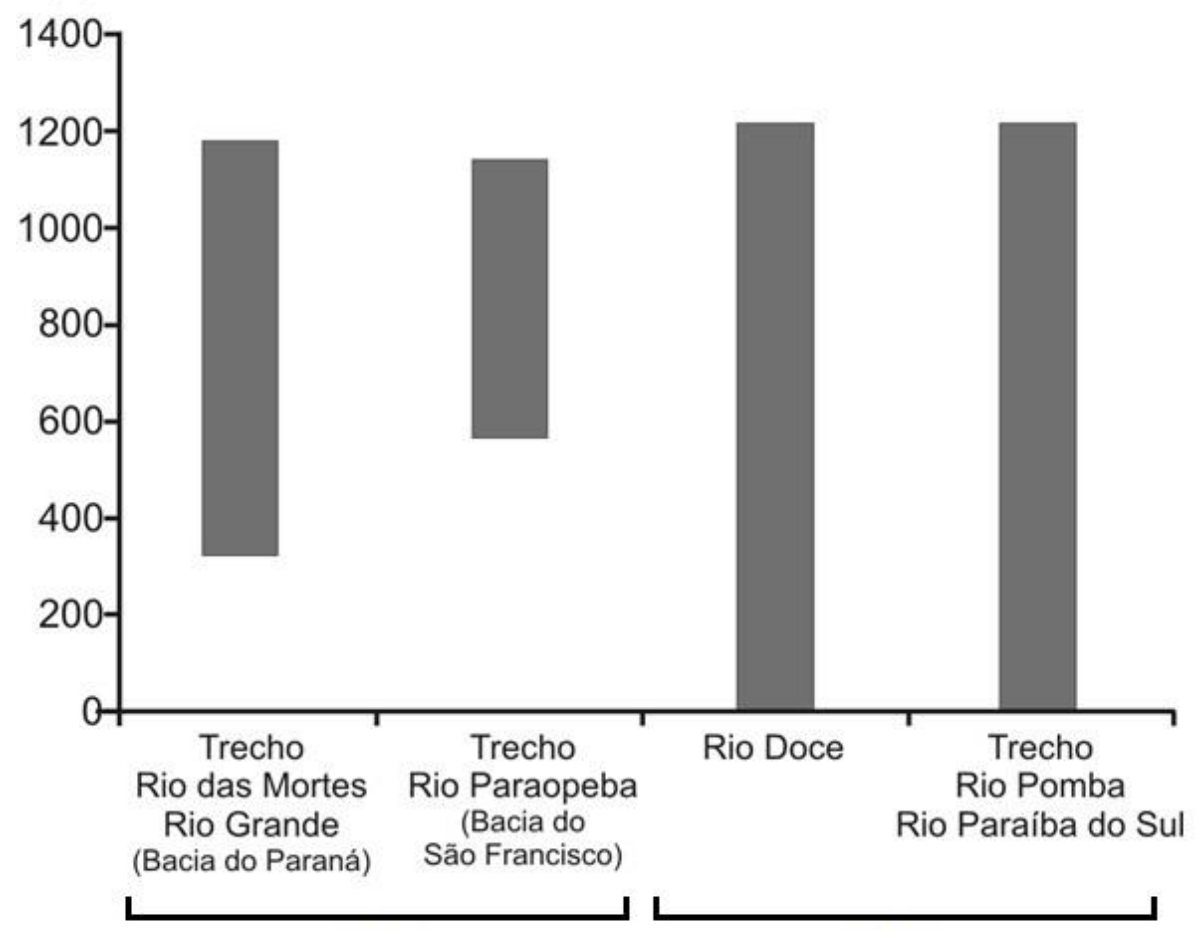

(i) (ii)

De acordo com Gilchrist et al. (1994) e Van der Beek et al. (2002) a evolução de algumas porções do relevo no interior dessas margens passivas ocorreria através da degradação do planalto por incisão vertical, com a formação do divisor hidrográfico após a ruptura continental localizado no interior separando bacias costeiras e interioranas. Eles avaliaram que a rede hidrográfica drenando planalto mais levado em direção à escarpa exibe denudação por incisão vertical que o degrada devido a elevada área de contribuição de fluxos de drenagem já estabelecidos. Isso levaria a destruição da escarpa original pela incisão vertical da rede de drenagem já estabelecida e a formação de uma nova próxima do divisor hidrográfico. Contribuiriam, ainda, para esse processo, a diferença de nível de base entre o topo da escarpa e o oceano, levando ao rebaixamento do curso fluvial principal por avanço remontante de vaga erosiva na região do kinckpoint junto à escarpa.

Entretanto, na área de estudo o quadro geomorfológico atual mostra o divisor hidrográfico do Grande Escarpamento que separa as bacias costeiras das interioranas a cerca de $270 \mathrm{Km}$ do oceano em linha reta (Figura 7). Por sua vez, a extensão dos cursos fluviais das bacias costeiras (Doce e Pomba) se distingue de maneira significativa, sendo a do rio Doce muito superior. Tal fato se deve ao arranjo espacial dos cursos fluviais dessas bacias. $O$ rio Pomba exibe caráter predominantemente linear, de direção WNW-ESSE até o litoral, cortando serras paralelas à costa. O rio Doce mostra direção NESW paralela à costa que se flexiona a WNW-ESSE, próximo ao município de Divino das Laranjeiras, em direção ao oceano onde também corta serras paralelas à costa.

As características morfológicas das bacias dos rios Doce e Pomba/Paraíba do Sul não sugerem evolução por recuo contínuo da escarpa. A morfologia na bacia do rio Doce com pronunciada inflexão, bem como a existência de elevações paralelas à costa em ambas as bacias são indício disso. Tal contexto geomorfológico permite excluir o processo de recuo contínuo por parte do Grande Escarpamento que se apresenta no contexto regional paralelo a outras serras, como da Mantiqueira e do Mar. O processo que mais se adéqua à área analisada é de degradação do planalto a partir de vaga erosiva ao longo dos principais cursos fluviais (rios Doce e Pomba), à semelhança das 
propostas de Gilchrist et al. (1994) e Van der Beek et al. (2002). Esse processo de degradação das bacias costeiras, até hoje vigente, esteve de início submetido a inequívoco condicionamento tectônico, porém, adentrada fase pós-rifte e tendo a margem continental alcançada maturidade, a penetração remontante de vaga erosiva instalou em definitivo o Grande Escarpamento que reproduz relevo altamente dissecado.

Figura 7: Organização regional da rede hidrográfica em que se insere a área de estudo e localização dos perfis intempéricos datados por ${ }^{40} \mathrm{Ar} /{ }^{39} \mathrm{Ar}$ na região do Planalto Atlântico, segundo Carmo e Vasconcelos (2004) e Carmo (2005).

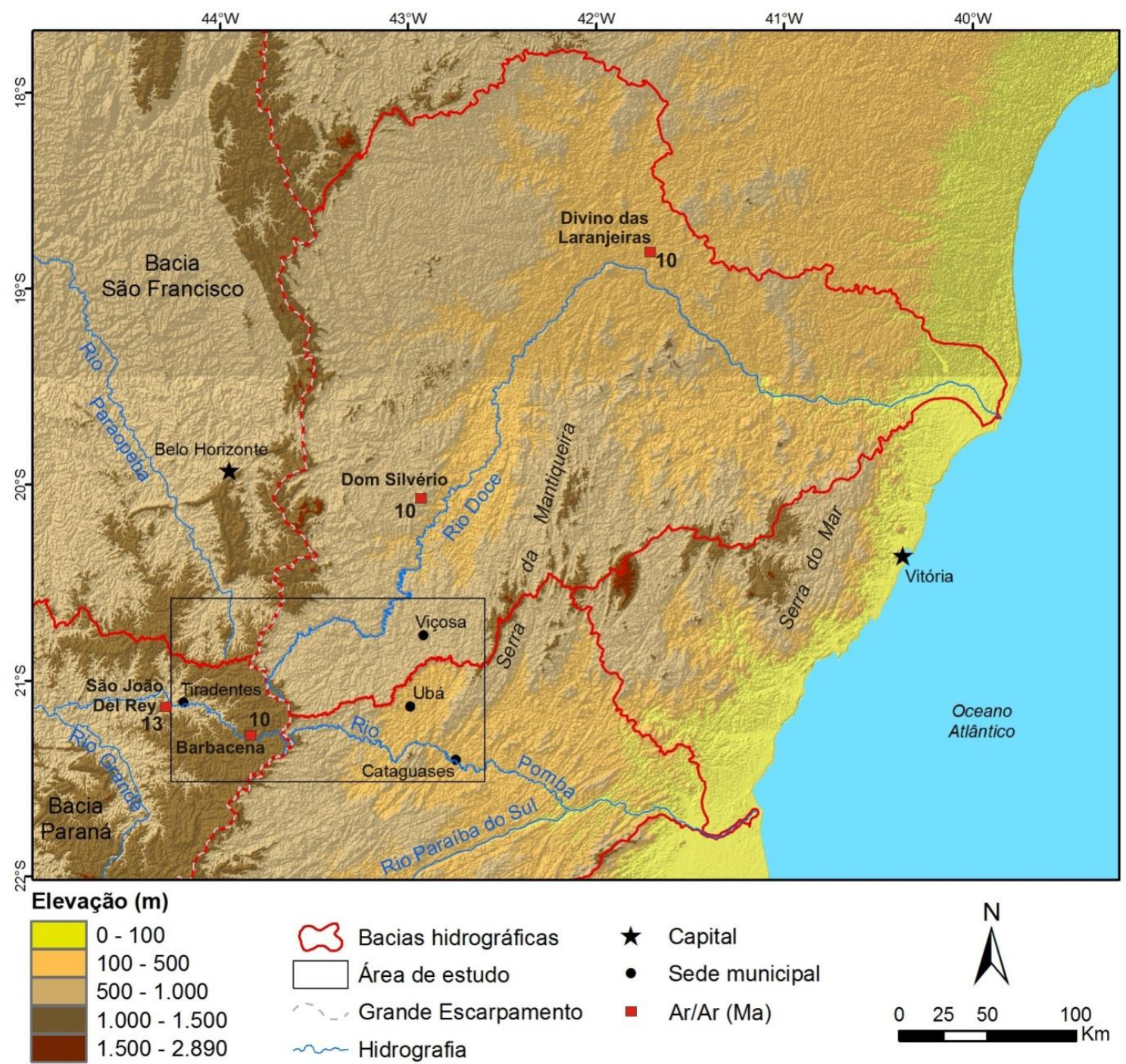

Um planalto mais elevado adjacente ao oceano pode ser inferido a partir de dados palinológicos levantados por Maizatto et al. (2009) que indicaram paleoflora a altitudes em torno dos $3.000 \mathrm{~m}$ na região da foz do rio Doce, no Cretáceo Superior (72 a $65 \mathrm{Ma}$ ). Essas altitudes são compatíveis com os trabalhos de Carmo et al. (2004) e Carmo (2005), na área de estudo, que estimaram denudação na região costeira $>2,5 \mathrm{Km}$ através de dados de traço de fissão de apatita.

A investigação e datação absoluta de perfis intempéricos localizados topograficamente acima e abaixo do Grande Escarpamento contribuem sobremaneira com o refinamento do modelo evolutivo aqui exposto. Esses perfis, estejam eles localizados nas bacias interioranas ou costeiras, registraram idades ${ }^{40} \mathrm{Ar} /{ }^{39} \mathrm{Ar}$ de $\sim 13-8 \mathrm{Ma}$, obtidas em solos com espessura média de 40-80 m (Figura 7; Tabela 
1). Embora localizados em contextos geomorfológicos distintos, a espessura e idades semelhantes desses perfis intempéricos sugerem que o manto de alteração tanto acima como abaixo do Grande Escarpamento constitui herança de processos geoquímicos iniciados no Mioceno tardio, quando os degraus escalonados das bacias do Paraná/São Francisco e Doce/Paraíba do Sul já se encontravam individualizados. Complementarmente, essas datações apontam ainda para uma possível discrepância cronológica quanto aos solos regionais, de tal modo que são mais antigos os perfis intempéricos posicionados acima do Grande Escarpamento ( 13 Ma; 10-8 Ma). Quanto àqueles solos posicionados abaixo do Grande Escarpamento, as idades ${ }^{40} \mathrm{Ar} /{ }^{39} \mathrm{Ar}$ indicam certa similaridade cronológica ( 10-8Ma). Tais dados permitem atribuir a formação dessa escarpa no máximo até o final do Mioceno Inferior individualizando dois grupos distintos de bacias, um costeiro e outro para o interior continental.

Tabela 1: Idades de intemperismo datados por ${ }^{40} \mathrm{Ar}{ }^{39} \mathrm{Ar}$ na região do Planalto Atlântico, segundo Carmo e Vasconcelos (2004) e Carmo (2005). Os dados são apresentados segundo localização dos perfis intempéricos: (i) acima e (ii) abaixo do Grande Escarpamento.

\begin{tabular}{llcccc}
\multicolumn{2}{l}{ Município } & Bacia hidrográfica & $\begin{array}{c}\text { Altitude } \\
\mathbf{( m )}\end{array}$ & $\begin{array}{c}\text { Espessura } \\
\mathbf{( m )}\end{array}$ & $\begin{array}{c}\text { Idade } \\
\mathbf{( M a})\end{array}$ \\
\hline (i) & São João Del Rey & Paraná & 1040 & 60 & 13 \\
\cline { 2 - 6 } & Barbacena & Paraná & 1140 & $40-80$ & $10-8$ \\
\hline (ii) & Dom Silvério & Doce & 1118 & $40-80$ & $10-8$ \\
\cline { 2 - 6 } & Divino das Laranjeiras & Doce & 300 & $40-80$ & $10-8$ \\
\hline
\end{tabular}

\section{NÍVEL DE BASE DAS BACIAS COSTEIRAS}

A longa distância percorrida até o oceano pela rede hidrográfica que integra as bacias que drenam para o interior continental, apesar de entrecortada por rupturas de declive em seus perfis longitudinais (knickpoints), não se traduzem efetivamente na sua maior intensidade de dissecação quando comparadas às bacias topograficamente posicionadas abaixo do Grande Escarpamento. Não obstante, essas últimas (Doce/Paraíba do Sul), além de revelarem maior taxa de denudação, ocupam distintos degraus topográficos (intermediário e inferior; Figura 3). Essa organização em degraus denota a presença de níveis de base locais marcadamente associados a knickpoints de considerável desnivelamento altimétrico, que exercem papel fundamental na denudação das bacias costeiras, sem, contudo, implicarem em significativas diferenças na intensidade de dissecação (Figura 8).

O rio Doce, na área de estudo, exibe nível de base local a $\sim 600 \mathrm{~m}$ e comprimento total de $\sim 883$ $\mathrm{km}$, enquanto o rio Pomba (bacia do Paraíba do Sul) exibe nível de base local a $\sim 400 \mathrm{~m}$ e comprimento total $439 \mathrm{~km}$ (Figuras 7 e 8 ). Esse último apresenta comprimento $~ 50 \%$ menor que o rio Doce, estando mais próximo do nível de base geral, uma das razões que explica seu nível de base local mais baixo, cerca $200 \mathrm{~m}$. Entretanto, a ocorrência de depósitos turbidíticos que nas bacias sedimentares do Espírito Santo (FRANÇA et al. 2007) e de Campos (WINTER et al. 2007) preenchem paleocânions (FRANÇA et al. 2007; SCHREINER et al., 2008; 2009), sugere que a rede hidrográfica da bacia do rio Doce se articulou ao nível de base geral a cerca de $100 \mathrm{Ma}$, ao passo que essa articulação teria sido mais tardia na bacia do rio Paraíba do Sul (93 Ma). Contudo, em ambas bacias, a distância em linha reta do oceano até suas cabeceiras é proporcionalmente a mesma.

$\begin{array}{llllll}\text { Caminhos de Geografia } & \text { Uberlândia - MG } & \text { v. 19, n. } 68 & \text { Dez/2018 } & \text { p. 215-232 } & \text { Página } 226\end{array}$


Figura 8: Perfis longitudinais e principais knickpoints dos rios Doce e Pomba/Paraíba do Sul. Em A, os perfis de ambos os rios são representados conjuntamente. Em B, esses mesmos perfis, individualizados, mostram a localização dos principais knickpoints e os compartimentos do relevo em que se encontram inseridos.

A)

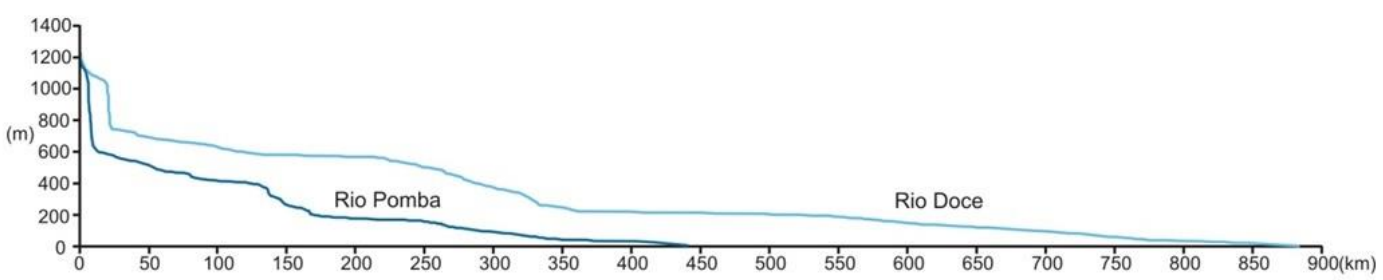

B)
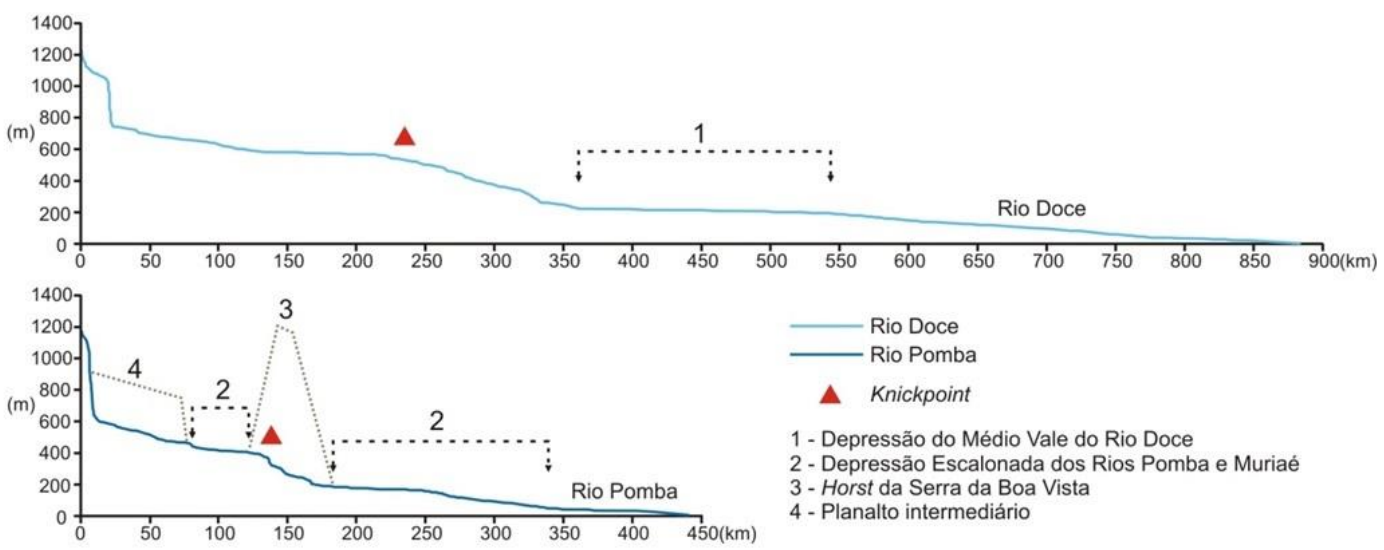

1 - Depressão do Médio Vale do Rio Doce

2 - Depressão Escalonada dos Rios Pomba e Muriaé

3 - Horst da Serra da Boa Vista

4 - Planalto intermediário

A organização espacial das bacias do rio Doce e Pomba no que tange à sua geometria e evolução está associada ao seu condicionamento estrutural (Figura 9). A bacia do rio Doce em seu médio e alto curso se organiza segundo a direção NNE-S-SW, associada a estruturas de mesma direção. A bacia do rio Pomba em seu médio e alto curso se organiza segundo direção NW-SE e no baixo curso, inserido no baixo Paraíba do Sul, a NE-SW, ambas as direções segundo controles estruturais regionais. Tal configuração espacial entre drenagem e estruturas permite entender a dissecação semelhante nas bacias dos rios Pomba e Doce, mesmo a primeira tendo se articulado mais tardiamente ao oceano, uma vez que o controle estrutural sobre essa foi mais efetivo na superimposição de rede de drenagem de forma mais direta até o oceano.

A ocorrência de um planalto intermediário na bacia do rio Pomba/Paraíba do Sul é aqui considerada como remanescente de antiga superfície regional, cuja gênese está atrelada à própria formação do Grande Escarpamento durante o Mioceno Inferior. Durante esse processo de formação o nível de base dessa bacia era mais elevado e sua extensão areal consideravelmente maior que a atual. Fatores litológicos, estruturais e tectônicos estiveram associados à manutenção desse nível de base mais elevado e ao seu posterior rebaixamento.

O nível de base local na bacia do rio Pomba/Paraíba do Sul se encontra no Horst da Serra da Boa Vista, configurando um knickpoint (Figura 8) estruturalmente alicerçado em uma coleção de gnaisses enderbíticos, paragnaisses e charnockitos. Na área aqui investigada, Meis et al. (1982) consideraram os charnockitos as rochas mais resistentes à denudação, o que segundo Brandalise e Viana (1993) justificaria a ocorrência na área de proeminentes cúpulas rochosas - os 'pães de açúcar'. Noce et al. (2003) também salientaram a resistência dos paragnaisses quanto aos ortognaisses que os circundam. Por sua vez, Romano e Castañeda (2006) interpretaram níveis bauxíticos posicionados entre as cotas de 700 e 900 m, no Horst da Serra da Boa Vista, como provenientes de soerguimentos tectônicos. Para esses autores, a gênese dos níveis bauxíticos esteve relacionada a extenso pediplano regional relativamente bem irrigado por sistema de drenagem volumoso. Nesse sentido, tanto o soerguimento desse horst quanto a sua maior resistência à denudação, poderiam manter a porção montante da bacia do rio Pomba mais elevada por tempo suficientemente longo para

$\begin{array}{llllll}\text { Caminhos de Geografia } & \text { Uberlândia - MG } & \text { v. 19, n. 68 } & \text { Dez/2018 } & \text { p. 215-232 } & \text { Página } 227\end{array}$


elaboração de uma superfície regional hoje localizada entre as bacias dos rios Doce e Pomba/Paraíba do Sul.

Figura 9: Organização regional dos principais lineamentos estruturais presentes na área investigada.

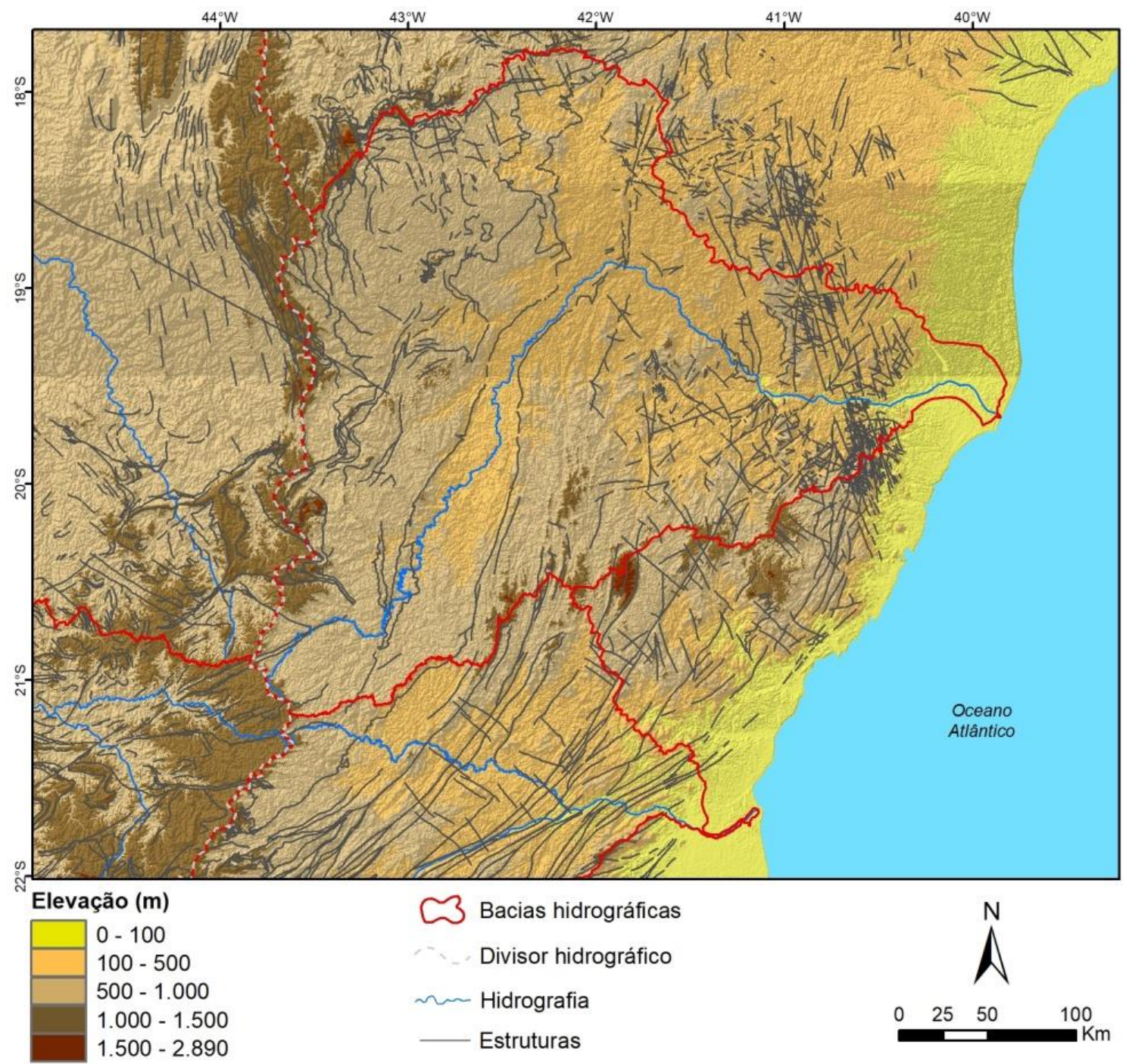

Fonte: SALVADOR et al., 2004; folhas Belo Horizonte SE 23, Rio Doce SE 24, Rio de Janeiro SF 23 e Vitória SF 24.

Após a formação do Grande Escarpamento até o Mioceno Inferior é possível que a região a montante do Horst da Serra da Boa Vista (Figuras 3 e 8) tenha se mantido temporariamente em cotas concordantes com a bacia do rio Doce, à semelhança do atual planalto intermediário no interior da bacia do rio Pomba, devido à atuação conjugada de resistência litológica e soerguimento tectônico do horst. Esse soerguimento teria sido facilitado por grande conjunto de estruturas NE-SW concordantes com a orientação desse pilar tectônico, a qual concorda também com a orientação da depressão adjacente, estruturas essas compiladas por Marent e Valadão (2015). Esses autores identificaram, ainda, na bacia do rio Pomba, seis níveis topográficos escalonados com caimento a SE, compartimentados segundo estruturas mapeadas em diferentes escalas espaciais, sendo o nível mais elevado constituído pelo Horst da Serra da Boa Vista. 
Digno de nota é o fato de a área que compreende o nível de base da bacia do rio Pomba/Paraíba do Sul estar inserida na Depressão Escalonada dos Rios Pomba e Muriaé, cujo contexto geomorfológico, segundo Mello et al. (2005) e Silva (2012), revela condicionantes morfotectônicos semelhantes vigentes tanto na Depressão do Médio Vale do Rio Doce como no Rift Continental do Sudeste do Brasil. Ambos os autores, a partir de perfis em varredura reconheceram blocos abatidos, soerguidos e basculados adjacentes ao Horst da Serra da Boa Vista que se estendem da Serra da Mantiqueira até a Serra do Mar, numa típica estruturação de hemigrábens. Na Depressão Escalonada dos Rios Pomba e Muriaé, Mello et al. (2005) identificaram dois eventos tectônicos durante o Pleistoceno Superior, admitindo ainda uma fase mais antiga atribuída à geração do Rift Continental do Sudeste do Brasil. Nesse sentido, é possível que o nível de base mais baixo nessa bacia, em relação à do rio Doce, seja consequência de retroalimentações advindas da relação entre tectônica e denudação.

Como já salientado anteriormente, entre 100 a 93 Ma teve início a denudação das bacias costeiras em articulação ao nível de base do oceano, escala temporal insuficiente para imprimir uma dissecação diferenciada entre as bacias do rio Pomba/Paraíba do Sul e do rio Doce. Os eventos que levaram ao maior rebaixamento da primeira em relação à essa segunda bacia ocorreram a partir do Mioceno Inferior, quando teve início o desmonte denudacional da superfície mais elevada (atual planalto intermediário; bacia do alto rio Doce) a partir do nível mais baixo (bacia do rio Pomba/Paraíba do Sul). Nesse sentido, Cherem et al. (2012) concluíram que a taxa de denudação quaternária foi mais elevada na escarpa da bacia do rio Paraíba do Sul que aquela vigente no planalto em que se insere a bacia do rio Doce.

\section{CONSIDERAÇÕES FINAIS}

Os procedimentos utilizados neste trabalho permitiram reconhecer e caracterizar o papel fundamental exercido pelos elementos do relevo (hipsometria e dissecação), da drenagem (dimensão, amplitude e extensão), estruturais, tectônicos e da organização espacial das bacias hidrográficas na gênese e evolução do cenário geomorfológico de trecho da porção sudeste de Minas Gerais.

O nível de base, nas escalas dimensional e temporal analisadas neste trabalho, revelou-se condicionante fundamental na organização da configuração do relevo. Uma complexa relação decorrente da relação verificada entre a amplitude dos principais canais fluviais das bacias hidrográficas que drenam a área investigada e seus distintos níveis de base desencadeou processos responsáveis pela sua maior ou menor dissecação. As diferenças entre os níveis de base das bacias costeiras e do interior continental foram responsáveis pela contrastante denudação que se verifica nessas bacias, sendo ela mais elevada na porção voltada diretamente para o oceano. Essa elevada dissecação nas bacias costeiras decorre de sua conexão direta ao nível de base geral, o oceano, enquanto as bacias do interior continental apresentam dissecação intermediária, submetida a níveis de base posicionados em maior altitude. O limite espacial da contrastante dissecação em curso nas bacias costeiras e interioranas coincide com o traçado em planta do Grande Escarpamento, cuja formação teve início até o Mioceno Inferior, inaugurando seu recuo continente adentro, processo esse ainda vigente.

As bacias hidrográficas do interior continental (Paraná e São Francisco) são mais extensas que as bacias costeiras (Doce e Paraíba do Sul). Os afluentes que drenam em direção ao interior continental (rio das Mortes/Grande, bacia do Paraná; e Paraopeba, bacia do São Francisco) exibem desníveis significativamente menores quando comparados aos afluentes que drenam diretamente para o oceano (rios Doce e Pomba, bacia do Paraíba do Sul). Ademais, as bacias costeiras, quando comparadas entre si, exibem níveis de base locais em distintas altitudes, responsáveis pela organização em degraus entre elas. Esses degraus estão associados a knickpoints de grande amplitude que proporcionam denudação mais intensa na bacia do rio Pomba/Paraíba do Sul, do que aquela que caracteriza a bacia do alto rio Doce.

\section{REFERÊNCIAS}

ALMEIDA, F.F.M. The system of continental rifts bordering the Santos Basin, Brazil. Anais da Academia Brasileira de Geociências, v. 48, p. 15-26 (suplemento), 1976.

$\begin{array}{llllll}\text { Caminhos de Geografia } & \text { Uberlândia - MG } & \text { v. 19, n. } 68 & \text { Dez/2018 } & \text { p. 215-232 } & \text { Página } 229\end{array}$


ANA - Agência Nacional das Águas. Arquivos digitais. 2014. Disponível em:

<http://hidroweb.ana.gov.br/HidroWeb.asp?Tocltem=4100 >. Acesso em: 15/06/2014.

BRANDALISE, L.A.; VIANA, H.S. Programa de Levantamentos Geológicos Básicos do Brasil. Folha Rio Pomba - texto explicativo. Escala 1:100.000. Org. BRANDALISE, L. A.; VIANA, H, S. Brasília, DNPM-CPRM, 1993. 176p.

CARMO, I.O. Geocronologia do intemperismo cenozóico no sudeste do Brasil. 2005. 134 f. Tese (Doutorado) - UFRJ, Rio de Janeiro, 2005.

CARMO, I.O.; VASCONCELOS, P.M. Geochronological evidence for pervasive Miocene weathering, Minas Gerais, Brazil. Earth Surface Processes and Landforms, 29, 1303-1320, 2004. https://doi.org/10.1002/esp.1090

CARMO, I.O; VASCONCELOS, P.M.; KOHN, B.; Geocronologia de intemperismo, termocronologia por traços de fissão de apatita e preservação de antigas superfícies Geomorfológicas, Quadrilátero Ferrífero, SE Brasil. In: CONGRESSO BRASILEIRO DE GEOLOGIA, 42., 2004, Araxá. Anais... Araxá: SBG, 2004.

CHEREM, L.F.S. Morfo-pedogênese das bordas dos planaltos escalonados do sudeste mineiro. 2012. 96 f. Tese (Doutorado) - Universidade Federal de Ouro Preto, 2012.

CHEREM, L.F.S.; VARAJÃO, C.A.C.; BRAUCHER, R.; BOURLÈS, D.; SALGADO, A.A.R.; VARAJÃO, A.C. Long-term evolution of denudational escarpments in southeastern Brazil. Geomorphology, 173174, p. 118-127, 2012. https://doi.org/10.1016/j.geomorph.2012.06.002

COCKBURN, H.A.P.; BROWN, R.W.; SUMMERFIELD, M.A.; SEIDL, M.A. Quantifying passive margin denudation and landscape development using a combined fission-track thermochronology and cosmogenic isotope analysis approach. Earth and Planetary Science Letters, 179, p. 429-435, 2000. https://doi.org/10.1016/S0012-821X(00)00144-8

DRAGUT, L.; EISANK, C. Automated object-based classification of topography from SRTM data. Geomorphology, v. 141-142, n. 1, p. 21-33, 2012. https://doi.org/10.1016/i.geomorph.2011.12.001 FRANÇA, R.L.; DEL REY, A.C.; TAGLIARI, C.V.; BRANDÃO, J.R.; FONTANELLI, P.R. Bacia do Espírito Santo. Boletim de Geociências da Petrobrás. v. 15, n. 2, p.501-509, 2007.

GILCHRIST, A. R.; SUMMERFIELD, M. A. Differential denudation and flexural isostasy in formation of rifted-margin upwarps. Nature, v. 346, p.739-742, 1990. https://doi.org/10.1038/346739a0

GILCHRIST, A.R.; KOOI, H.; BEAUMONT, C. Post-Gondwana geomorphic evolution of southwestern Africa: implications for the controls on landscape development from observations and numerical experiments. Journal of Geophysical Research, v. 99, n. B6, p. 12,211-12,228, 1994. https://doi.org/10.1029/94JB00046

IBGE - Instituto de Geografia e Estatística. Manual técnico de Geomorfologia. Coordenação de Recursos Naturais e Estudos Ambientais. 2 ${ }^{\mathrm{a}}$ Ed. Rio de Janeiro: IBGE, 2009. 182 p.

INPE - Instituto de Pesquisa Espaciais. TOPODATA - Banco de Dados Geomorfométricos do Brasil. 2011. Disponível em: <http://www.dsr.inpe.br/topodata>. Acesso em: 26 dez 2011.

MACEDO, J.M. Evolução tectônica da Bacia de Santos e áreas continentais adjacentes. Boletim de Geociências da Petrobrás, v. 3, n.3, p. 159-173, 1989.

MAIZATTO, J.R.; LANA, C.C.; RIBEIRO, A.W.S.; FERREIRA, E.P. Evidências de terras altas no Campaniano da Bacia do Espírito Santo. Boletim de Geociências da Petrobrás, v. 17, n. 1, p. 3143, 2009.

MANFRÉ, L.A.; NÓBREGA, R.A.A.; QUINTANILHA, J.A. Regional and local topography subdivision and landform mapping using SRTM-derived data: a case study in southeastern Brazil. Environmental Earth Sciences (Internet), v. 73, p. 6457-6475, 2015. https://doi.org/10.1007/s12665-014-3869-2

MATMON, A.; BIERMAN, P.; ENZEL, Y. Pattern and tempo of great escarpment erosion. Geology, v. 30, n. 12, p. 1135-1138, 2002. https://doi.org/10.1130/0091-

7613(2002)030<1135:PATOGE >2.0.CO;2 
MARENT, B.R.; VALADÃO, R.C. Compartimentação geomorfológica dos planaltos escalonados do sudeste de Minas Gerais - Brasil. Revista Brasileira de Geomorfologia, v.16, n. 2, p. 255-270, 2015. https://doi.org/10.20502/rbg.v16i2.634

MEIS, M.R.M.; MIRANDA, L.H.G.; FERNANDES, N.F. Desnivelamento de altitude como parâmetros para a compartimentação do relevo: bacia do médio-baixo Paraíba do Sul. In: CONGRESSO BRASILEIRO DE GEOLOGIA, 32., 1982, Salvador. Anais..., Salvador: SBG, v. 4, 1982, p. 14891503.

MELLO, C.L.; TOMAZ, E.A.; SILVA, R.C.B.; RODRIGUES, H.B. Condicionamento tectônico Cenozóico na evolução da depressão topográfica dos rios Pomba e Muriaé (MG, RJ). In: SIMPÓSIO NACIONAL DE ESTUDOS TECTÔNICOS, 10., 2005, Curitiba (PR). Boletim de resumos expandidos... Curitiba: [s.n.], v. 1, 2005. p. 192-194.

NOCE, C.M.; ROMANO, A.W.; PINHEIRO, C.M.; MOL, V.S.; SOARES, A.C.P. Geologia das Folhas Ubá e Muriaé. In: PEDROSA-SOARES, A. C.; NOCE, C.M.; TROUW, R. A. J.; HEILBRON, M. Geologia e recursos minerais do sudeste mineiro: Volume III. Projeto Sul de Minas-Etapa I (COMIG-UFMG-UFRJ-UERJ), COMIG, 2003. p. 623-659.

NOTT, J.; HORTON, S. 180 Ma continental drainage divide in northeastern Australia: role of passive margin tectonics. Geology, v. 28, n. 8, p. 763-766, 2000. https://doi.org/10.1130/00917613(2000)28<763:MCDDIN>2.0.CO;2

OLLIER, C.D.; PAIN, C.F. Equating the basal unconformity with the palaeoplain: a model for passive margins. Geomorphology, 19, p. 1-15, 1997. https://doi.org/10.1016/S0169-555X(96)00048-7

ROMANO, A.W.; CASTAÑEDA, C.A. Tectônica distensiva pós-mesozóica no condicionamento dos depósitos de bauxita da zona da mata mineira. Geonomos, v. 14, n. 1,2, p. 1-5, 2006.

SAADI, A. Ensaio sobre a morfotectônica de Minas Gerais (tensões intraplacas, descontinuidades crustais e morfogênese). 1991. 285 f. Tese para professor titular - Instituto de Geociências, UFMG, Belo Horizonte, 1991.

SALGADO, A.A.R.; SOBRINHO, L.C.G.; CHEREM, L.F.S.; VARAJÃO, C.A.C.; BOURLÈS, D.; BRAUCHER, R.; MARENT, B.R. Estudo da evolução da escarpa entre as bacias do Doce/Paraná em Minas Gerais através da quantificação das taxas de desnudação. Revista Brasileira de Geomorfologia, v. 13, n.2, p. 213-222, 2012. https://doi.org/10.20502/rbg.v13i2.280

SALGADO, A.A.R.; MARENT, B.R.; CHEREM, L.F.S.; BOURLÈS, D.; SANTOS, L.J.C.; BRAUCHER, R.; BARRETO, H.N. Denudation and retreat of the Serra do Mar escarpment in southern Brazil derived from in situ-produced ${ }^{10} \mathrm{Be}$ concentration in river sediment. Earth Surface Progress and Landforms. 39, 311-319, 2014. https://doi.org/10.1002/esp.3448

SANTOS, R.D.; LEMOS, R.C.; SANTOS, H.G.; KER, J.C.; ANJOS, L.H.C. Manual de descrição e coleta de solo no campo. $5^{\mathrm{a}}$ edição. Viçosa: Sociedade Brasileira de Ciência do Solo, 2005. 92p.

SALVADOR, E. D., Folha Belo Horizonte SE 23, Rio Doce SE 24, Rio de Janeiro SF 23 e Vitória SF 24. In: PERROTA, M.M.; D'AGOSTINHO, L.Z.; et al. Carta Geológica do Brasil ao Milionésimo GIS Brasil, escala 1:100.000, 2004. 1 CDrom.

SCHREINER, S.; SOUZA, M.B.F.M.; MIGLIORELLI, J.P.R. Modelo digital da Geomorfologia do fundo oceânico da Bacia de Campos. Boletim de Geociências da Petrobrás, v. 16, n. 1, 157-160, 2008.

SCHREINER, S.; SOUZA, M.B.F.M.; MIGLIORELLI, J.P.R. Modelo digital da Geomorfologia do fundo oceânico centro-sul da Bacia do Espírito Santo e norte da Bacia de Campos. Boletim de

Geociências da Petrobrás, v. 17, n. 2, 365-369, 2009.

SILVA, T.P. Modelo geológico-geomorfológico da evolução da bacia hidrográfica do Rio Paraíba do Sul. 2012. 139 f. tese (Doutorado) - UFRJ, Rio de Janeiro, 2012.

SOUZA, C.J.O. Interpretação morfotectônica da bacia do Rio Doce. 1995. 146 f. Dissertação (Mestrado) - Instituto de Geociências, Universidade Federal de Minas Gerais, 1995.

SUMMERFIELD, M.A. Global Geomorphology: an introduction of the study of landforms. Essex, Longman Scientific \& Technical, 1991. 537p.

$\begin{array}{llllll}\text { Caminhos de Geografia } & \text { Uberlândia - MG } & \text { v. 19, n. } 68 & \text { Dez/2018 } & \text { p. 215-232 } & \text { Página } 231\end{array}$


THOMAS, M.F.; SUMMERFIELD, M.A. Long-term landform development: key themes and research problems. In: GARDINER, V. International Geomorphology. Edited by: Jonh Wiley \& Sons Ltd., part II, 1987. p: 935-956.

VALADÃO, R.C. Evolução de longo-termo do relevo do Brasil oriental (desnudação, superfícies de aplanamento e soerguimentos crustais). 1998. 243 f. Tese (Doutorado) - UFBA, Salvador, 1998.

VALADÃO, R.C. Geodinâmica de superfícies de aplainamento, desnudação continental e tectônica ativa como condicionantes da megageomorfologia do Brasil Oriental. Revista Brasileira de Geomorfologia, v. 10, n. 2, p. 77-90, 2009. https://doi.org/10.20502/rbg.v10i2.132

VALERIANO, M.M. Curvatura vertical de vertentes em microbacias pela análise de modelos digitais de elevação. Revista Brasileira de Engenharia Agrícola e Ambiental, v. 7, n. 3, p. 539-546, 2003. https://doi.org/10.1590/S1415-43662003000300022

VALERIANO, M.M.; CARVALHO JÚNIOR, O.A. Geoprocessamento de modelos digitais de elevação para mapeamento da curvatura horizontal em microbacias. Revista Brasileira de Geomorfologia, v. 4, n. 1, p. 17-29, 2003. https://doi.org/10.20502/rbg.v4i1.17

VAN DER BEEK, P.; SUMMERFIELD, M.A.; BRAUN, J.; BROWN, R.W.; FLEMING, A. Modeling postbreakup landscape development and denudational history across the southeast African

(Drakensberg Escarpment) margin. Journal of Geophysical Research, v.107, n. B12, p. 1-13, 2002. https://doi.org/10.1029/2001JB000744

WINTER, R.W.; JAHNERT, R.J.; FRANÇA, A.B. Bacia de Campos. Boletim de Geociências da Petrobrás, v. 15, n. 2, p. 511-529, 2007.

ZALÁN, P.V.; OLIVEIRA, J.A.B. Origem e evolução estrutural do Sistema de Riftes Cenozóicos do Sudeste do Brasil. Boletim de Geociências da Petrobrás, v. 13, n. 2, p. 269-300, 2005.

Recebido em: 17/11/2017

Aceito para publicação em: 09/05/2018 